\title{
Effect of Ga, Nb Addition on Disproportionation Kinetics of Nd-Fe-B Alloy
}

\author{
H. W. Kwon ${ }^{1 *}$ and J. H. Yu ${ }^{2}$ \\ ${ }^{1}$ Pukyong National University, Busan 608-739, Korea \\ ${ }^{2}$ Korea Institute of Materials Science, Changwon 641-831, Korea
}

(Received 26 August 2009, Received in final form 9 October 2009, Accepted 9 October 2009)

\begin{abstract}
The effect of $\mathrm{Ga}$ and, $\mathrm{Nb}$ addition on the kinetics and mechanism of the disproportionation of a $\mathrm{Nd}-\mathrm{Fe}-\mathrm{B}$ alloy were investigated by isothermal thermopiezic analysis (TPA) using $\mathrm{Nd}_{12.5} \mathrm{Fe}_{(81.1-(\mathrm{x}+\mathrm{y}))} \mathrm{B}_{6.4} \mathrm{Ga}_{\mathrm{x}} \mathrm{Nb}_{\mathrm{y}}(\mathrm{x}=\mathbf{0}$ and $0.3, \mathrm{y}=$ $\mathrm{O}$ and 0.2 ) alloys. The addition of $\mathrm{Ga}$ and $\mathrm{Nb}$ retarded the disproportionation kinetics of the Nd-Fe-B alloy significantly, and increased the activation energy of the disproportionation reaction. The disproportionation kinetics of the $\mathrm{Nd}_{12.5} \mathrm{Fe}_{(81.1-(\mathrm{x}+\mathrm{y}))} \mathrm{B}_{6.4} \mathrm{Ga}_{\mathrm{x}} \mathrm{Nb}_{\mathrm{y}}$ alloys measured under an initial hydrogen pressure of 0.02 MPa were fitted to a parabolic rate law. This suggested that during the disproportionation of $N_{12.5} F_{(81.1-(x+y))} B_{6.4} G_{x} \mathbf{N b}_{y}$ alloys with an initial hydrogen pressure of $0.02 \mathrm{MPa}$, a continuous disproportionation product is formed and the overall reaction rate is limited by the diffusion of hydrogen atoms (or ions).
\end{abstract}

Keywords : permanent magnets, HDDR, disproportionation kinetics, activation energy, TPA

\section{Introduction}

The HDDR (hydrogenation, disproportionation, desorption and recombination) process is a useful means of producing a highly coercive Nd-Fe-B powder with a fine grain structure directly from an ingot alloy [1,2]. Depending on the control of the HDDR process variables, particularly in the disproportionation step, the final product can be either an isotropic powder or an anisotropic powder. In an isotropic powder, the recombined fine grains are oriented randomly. On the other hand, in an anisotropic powder, the recombined grains are oriented orderly (texture) in such a manner that the magnetisation easy axis (c-axis) of the neighbouring recombined $\mathrm{Nd}_{2} \mathrm{Fe}_{14} \mathrm{~B}$ grains is parallel to each other maintaining the crystallographic orientation of their mother grain [3-11]. For the production of highly anisotropic Nd-Fe-B alloy HDDR powder with good texture, the alloy is usually modified by adding $\mathrm{Ga}$ and, $\mathrm{Nb}$, and the disproportionation kinetics should be controlled carefully using a lower hydrogen pressure. Ga- and, $\mathrm{Nb}$ - addition increases the coercivity and remanence of the HDDR-treated Nd-Fe-B material, respectively $[5,12]$. $\mathrm{Nb}$ also helps stabilize the iron boride phase of the disproportionated phases, which acts as a memory site for the texture, and Ga is beneficial

*Corresponding author: Tel: +82-51-629-6362

Fax: +82-51-629-6353, e-mail: hwkwon@pknu.ac.kr for suppressing the excessive growth of the recombined grains $[9,13]$. It is believed that the addition of $\mathrm{Ga}$ and/or $\mathrm{Nb}$ may influence the disproportionation kinetics of the Nd-Fe-B alloy, of which careful control is of utmost importance for improving the texture of the recombined $\mathrm{Nd}_{2} \mathrm{Fe}_{14} \mathrm{~B}$ grains. This study examined the effect of $\mathrm{Ga}$ and, $\mathrm{Nb}$ addition on the kinetics and mechanism of the disproportionation of a Nd-Fe-B alloy.

\section{Experiment}

The $\mathrm{Nd}_{12.5} \mathrm{Fe}_{(81.1-(\mathrm{x}+\mathrm{y}))} \mathrm{B}_{6.4} \mathrm{Ga}_{\mathrm{x}} \mathrm{Nb}_{\mathrm{y}}(\mathrm{x}=0$ and $0.3, \mathrm{y}=0$ and 0.2 ) alloys used in the present study were prepared by arc-melting of the high purity constituent metals. The prepared alloy buttons were homogenised at $1413 \mathrm{~K}$ for $40 \mathrm{hr}$ in argon gas and then pulverised into powder with a particle size of $50 \sim 150 \mu \mathrm{m}$. The disproportionation kinetics of the powder material was examined by isothermal thermopiezic analysis (TPA). A powder (350 mg) was placed into the TPA reaction chamber with an approximate volume of $160 \mathrm{~cm}^{3}$. The chamber was evacuated and filled with hydrogen $(p=0.1 \mathrm{MPa})$. The sample was then heated to the desired disproportionation temperature $\left(T_{\mathrm{D}}\right)$ at rate of $7 \mathrm{~K} / \mathrm{min}$. During heating, the sample was fully hydrogenated up to $673 \mathrm{~K}$, at which temperature the hydrogen pressure in the reaction chamber was reduced to $0.01 \mathrm{MPa}$ by evacuating the reaction chamber. The fully hydrogenated sample was then heated continuously to the 


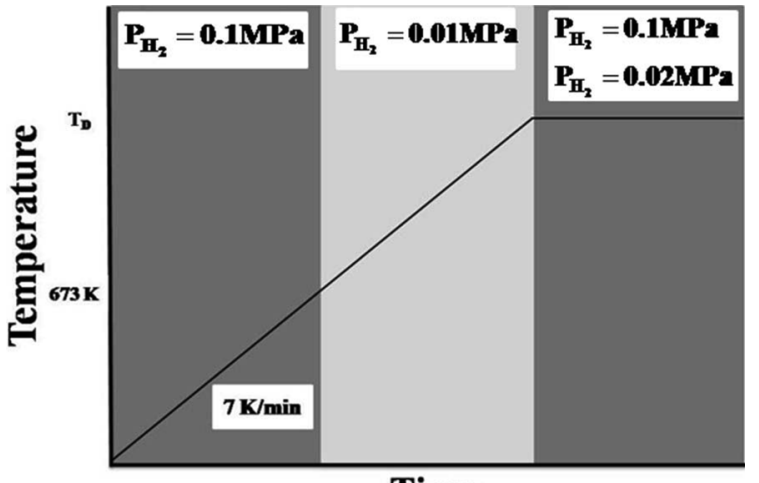

Time

Fig. 1. Experimental scheme for isothermal disproportionation.

desired disproportionation temperature. Heating under low hydrogen pressure $(0.01 \mathrm{MPa})$ prevented the fully hydrogenated alloy from any unwanted disproportionation until the desired isothermal disproportionation temperature had been reached. As soon as the sample reached the desired disproportionation temperature, the hydrogen pressure in the reaction chamber was increased to the desired pressure $(p=0.02,0.1 \mathrm{MPa})$ by introducing additional hydrogen gas. From this moment, the sample was kept at a constant temperature, and the decrease in hydrogen pressure due to hydrogen absorption during the disproportionation was measured. Fig. 1 shows a schematic diagram of the experimental scheme for isothermal disproportionation.

\section{Results and Discussion}

The overall disproportionation behaviour of the hydrogenated alloys was examined by heating the alloys con-

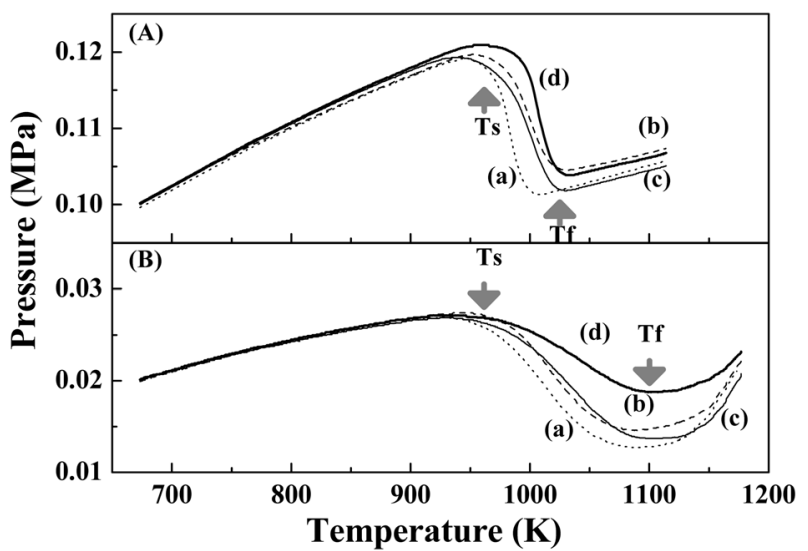

Fig. 2. TPA results during continuous heating under an initial hydrogen pressure of (A) 0.1 and (B) $0.02 \mathrm{MPa}$ for the disproportionation of the $\mathrm{Nd}_{12.5} \mathrm{Fe}_{(81.1-(\mathrm{x}+\mathrm{y}))} \mathrm{B}_{6.4} \mathrm{Ga}_{\mathrm{x}} \mathrm{Nb}_{\mathrm{y}}$ alloys. (a) $\mathrm{Nd}_{12.5} \mathrm{Fe}_{81.1} \mathrm{~B}_{6.4}$ (b) $\mathrm{Nd}_{12.5} \mathrm{Fe}_{80.8} \mathrm{~B}_{6.4} \mathrm{Ga}_{0.3}$ (c) $\mathrm{Nd}_{12.5} \mathrm{Fe}_{80.9} \mathrm{~B}_{6.4} \mathrm{Nb}_{0.2}$ (d) $\mathrm{Nd}_{12.5} \mathrm{Fe}_{80.6} \mathrm{~B}_{6.4} \mathrm{Ga}_{0.3} \mathrm{Nb}_{0.2}$. tinuously in hydrogen gas. Fig. 2 shows the TPA results showing the disproportionation of the fully hydrogenated $\mathrm{Nd}_{12.5} \mathrm{Fe}_{(81.1-(\mathrm{x}+\mathrm{y}))} \mathrm{B}_{6.4} \mathrm{Ga}_{\mathrm{x}} \mathrm{Nb}_{\mathrm{y}}$ alloy during the course of heating. The fully hydrogenated alloys were heated from approximately $673 \mathrm{~K}$ in the reaction chamber with an initial hydrogen pressure of 0.02 and, $0.1 \mathrm{MPa}$, and the pressure change was monitored during the course of heating. The hydrogen pressure appeared to increase up to approximately $950 \mathrm{~K}$ due to thermal expansion and then decrease abruptly due to disproportionation. The disproportionation start temperature $\left(T_{s}\right)$ was not influenced significantly by the hydrogen pressure, whereas the disproportionation completion temperature $\left(T_{f}\right)$ was. The $T_{f}$ is increased significantly under a lower hydrogen pressure. This suggests that the disproportionation kinetics is influenced significantly by the hydrogen pressure [14]. It should be noted that a pressure drop $(\Delta \mathrm{p})$ occurred in the interval from $T_{s}$ to $T_{f}$, which is equivalent to the amount of hydrogen absorption due to disproportionation, differs depending on the alloys. This is more profound in the results performed under a lower hydrogen pressure. The alloy with the combined addition of $\mathrm{Ga}$ and $\mathrm{Nb}$ appears to absorb much less hydrogen than that without $\mathrm{Ga}$ and $\mathrm{Nb}$. This suggests that the addition of $\mathrm{Ga}$ and/or $\mathrm{Nb}$ strongly affects the disproportionation kinetics of the Nd-Fe-B alloy. The effect of $\mathrm{Ga}$ and, $\mathrm{Nb}$ addition on the disproportionation kinetics of the Nd-Fe-B alloy can be seen more clearly in the isothermal TPA results. The fully hydrogenated $\mathrm{Nd}_{12.5} \mathrm{Fe}_{(81.1-(\mathrm{x}+\mathrm{y}))} \mathrm{B}_{6.4} \mathrm{Ga}_{\mathrm{x}} \mathrm{Nb}_{\mathrm{y}}$ alloys were subjected to isothermal disproportionation at $933 \mathrm{~K}$ with an initial hydrogen pressure $0.02 \mathrm{MPa}$, as shown in Fig. 3. The addition of $\mathrm{Ga}$ and, $\mathrm{Nb}$ retards the disproportionation kinetics of the Nd-Fe-B alloy significantly, and more

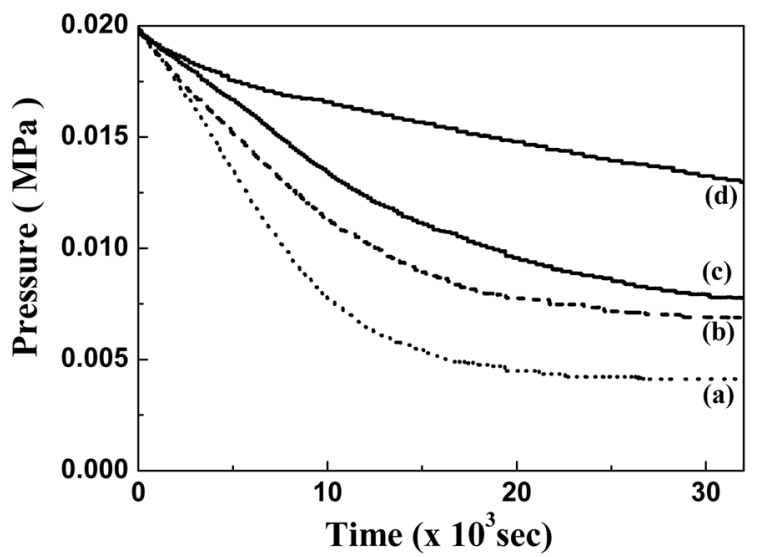

Fig. 3. Isothermal TPA results for the disproportionation of $\mathrm{Nd}_{12.5} \mathrm{Fe}_{(81.1-(\mathrm{x}+\mathrm{y}))} \mathrm{B}_{6.4} \mathrm{Ga}_{\mathrm{x}} \mathrm{Nb}_{\mathrm{y}}$ alloys carried out at $933 \mathrm{~K}$ under an initial hydrogen pressure of $0.02 \mathrm{MPa}$. (a) $\mathrm{Nd}_{12.5} \mathrm{Fe}_{81.1} \mathrm{~B}_{6.4}$ (b) $\mathrm{Nd}_{12.5} \mathrm{Fe}_{80.8} \mathrm{~B}_{6.4} \mathrm{Ga}_{0.3}$ (c) $\mathrm{Nd}_{12.5} \mathrm{Fe}_{80.9} \mathrm{~B}_{6.4} \mathrm{Nb}_{0.2}$ (d) $\mathrm{Nd}_{12.5^{-}}$ $\mathrm{Fe}_{80.6} \mathrm{~B}_{6.4} \mathrm{Ga}_{0.3} \mathrm{Nb}_{0.2}$. 


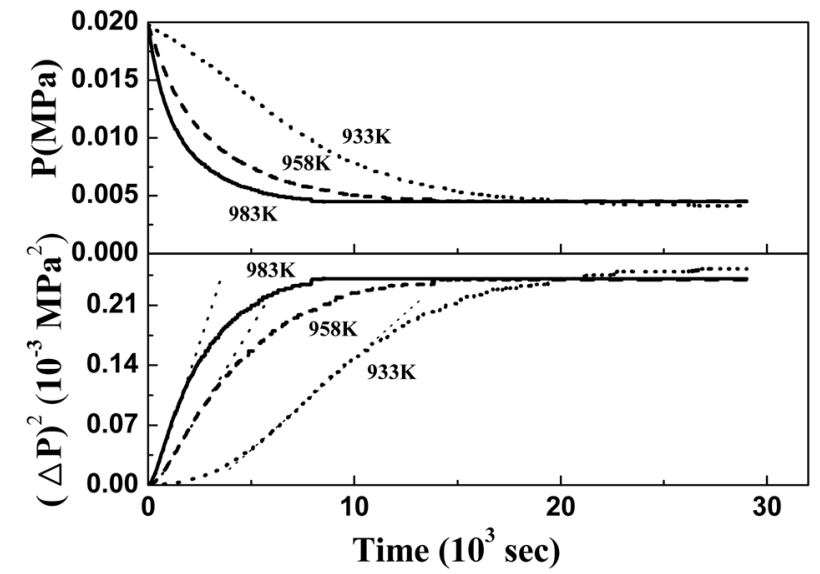

Fig. 4. Isothermal TPA result for the disproportionation of $\mathrm{Nd}_{12.5} \mathrm{Fe}_{81.1} \mathrm{~B}_{6.4}$ alloy carried out at various temperatures under an initial hydrogen pressure of $0.02 \mathrm{MPa}$.

profound retardation of the disproportionation kinetics was observed in the alloy containing both $\mathrm{Ga}$ and $\mathrm{Nb}$.

The effect of $\mathrm{Ga}$ and, $\mathrm{Nb}$ addition on the disproportionation kinetics of the Nd-Fe-B alloy was examined in more detail by isothermal TPA at various temperatures using the fully hydrogenated $\mathrm{Nd}_{12.5} \mathrm{Fe}_{(81.1-(\mathrm{x}+\mathrm{y}))} \mathrm{B}_{6.4} \mathrm{Ga}_{\mathrm{x}} \mathrm{Nb}_{\mathrm{y}}$ alloys. Isothermal TPA was carried out with an initial hydrogen pressure of $0.02 \mathrm{MPa}$, which is the hydrogen pressure commonly used in the disproportionation step for controlling the kinetics and achieving a high texture. An overall reaction rate equation of the disproportionation reaction was modelled and the activation energy was calculated using the isothermal TPA results at various temperatures. Fig. 4(a) shows the isothermal TPA results representing the disproportionation of hydrogenated ternary $\mathrm{Nd}_{12.5} \mathrm{Fe}_{81.1} \mathrm{~B}_{6.4}$ alloy at various temperatures with an initial hydrogen pressure of $0.02 \mathrm{MPa}$. The decrease in hydrogen pressure due to disproportionation occurred more rapidly as the temperature was increased. The overall reaction rate of the disproportionation of the hydrogenated $\mathrm{Nd}_{12.5} \mathrm{Fe}_{81.1} \mathrm{~B}_{6.4}$ alloy can be modelled using a parabolic rate equation,

$$
(\Delta p)^{2}=\kappa_{\mathrm{D}} t+C
$$

where $\Delta p$ is the pressure drop, $t$ is time, $\kappa_{\mathrm{D}}$ is the parabolic rate constant, and $C$ is a constant. A reaction demonstrating the parabolic rate yields a straight line when the data is plotted as $(\Delta p)^{2}$ versus time. Fig. 4(b) shows the fit of kinetic data to this model. The overall disproportionation kinetic data could be fitted more or less to a parabolic rate law, even though there was some deviation. This form of parabolic equation is typical of non-steady-state diffusion-controlled reactions. The dependence of $\kappa_{\mathrm{D}}$ on the temperature, $T$, is given by the Arrhenius

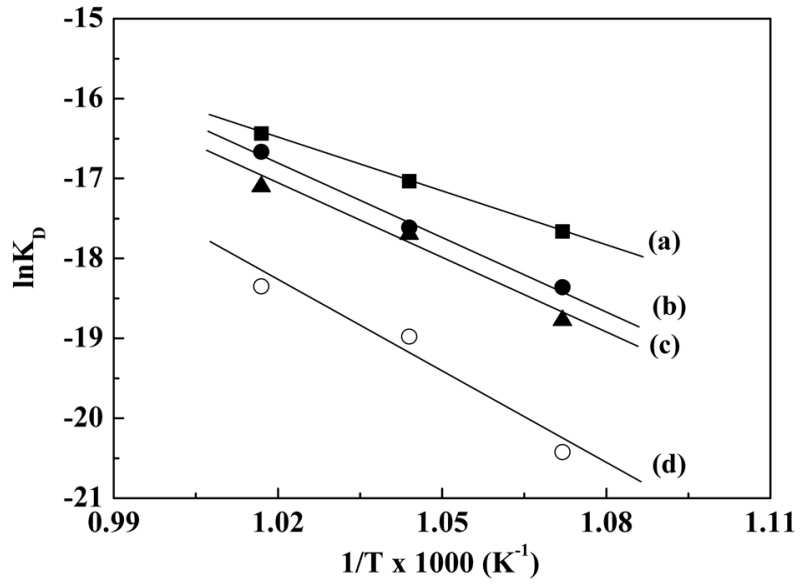

Fig. 5. Plot of $\ln \kappa_{\mathrm{D}}$ against $1 / \mathrm{T}$ for the disproportionation of $\mathrm{Nd}_{12.5} \mathrm{Fe}_{(81.1-(\mathrm{x}+\mathrm{y}))} \mathrm{B}_{6.4} \mathrm{Ga}_{\mathrm{x}} \mathrm{Nb}_{\mathrm{y}}$ alloys under a hydrogen pressure of $0.02 \mathrm{MPa}$. (a) $\mathrm{Nd}_{12.5} \mathrm{Fe}_{81.1} \mathrm{~B}_{6.4}$ (b) $\mathrm{Nd}_{12.5} \mathrm{Fe}_{80.8} \mathrm{~B}_{6.4} \mathrm{Ga}_{0.3}$ (c) $\mathrm{Nd}_{12.5} \mathrm{Fe}_{80.9} \mathrm{~B}_{6.4} \mathrm{Nb}_{0.2}$ (d) $\mathrm{Nd}_{12.5} \mathrm{Fe}_{80.6} \mathrm{~B}_{6.4} \mathrm{Ga}_{0.3} \mathrm{Nb}_{0.2}$.

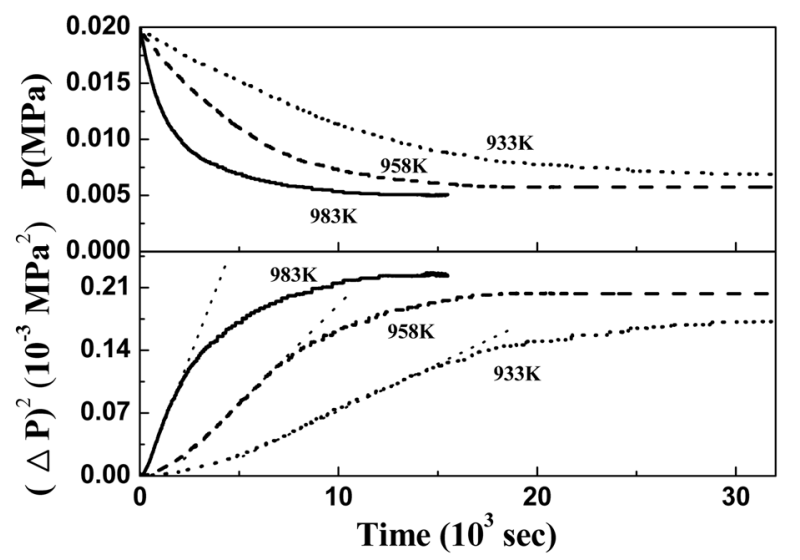

Fig. 6. Isothermal TPA result for the disproportionation of $\mathrm{Nd}_{12.5} \mathrm{Fe}_{80.8} \mathrm{~B}_{6.4} \mathrm{Ga}_{0.3}$ alloy carried out at various temperatures under an initial hydrogen pressure of $0.02 \mathrm{MPa}$.

equation:

$$
\kappa_{\mathrm{D}}=A \exp (-E / \mathrm{RT})
$$

where $A$ is a constant known as the frequency factor, $E$ is the activation energy for the reaction, and $R$ is the gas constant. The Arrhenius law can be tested by plotting $\ln$ $\kappa_{\mathrm{D}}$ as a function of the reciprocal absolute temperature. According to Eq. (2), the activation energy for the disproportionation of the $\mathrm{Nd}_{12.5} \mathrm{Fe}_{81.1} \mathrm{~B}_{6.4}$ alloy was estimated to be approximately $189 \mathrm{~kJ} / \mathrm{mol}$ from the slope of the straight line [-E/RT] (Fig. 5).

Fig. 6(a) 8(a) show the isothermal TPA results showing the disproportionation of the Nd-Fe-B alloys containing $\mathrm{Ga}$ and/or $\mathrm{Nb}$ carried out at various temperatures. Fig. 6(b) 8(b) gives the fits of the disproportionation kinetic data to the parabolic rate model. It appears that the disproportionation kinetic data of the $\mathrm{Ga}$ - and, $\mathrm{Nb}$ - 


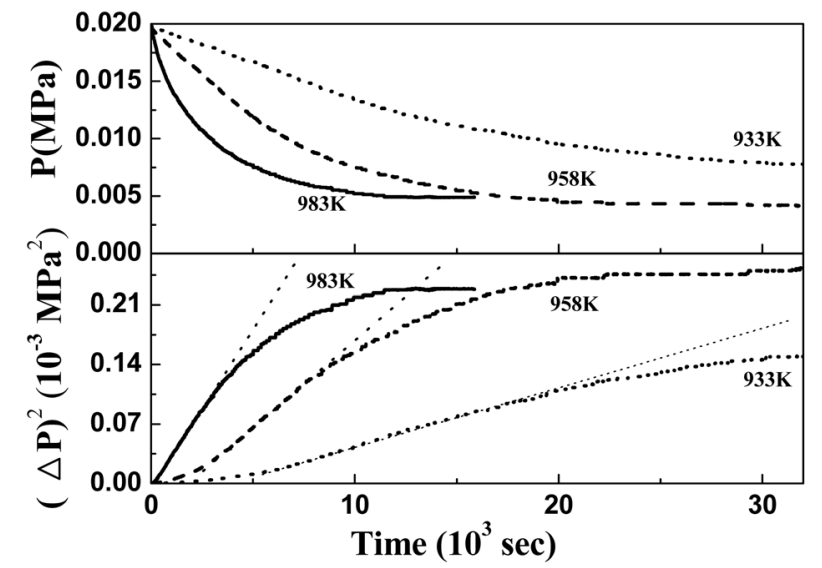

Fig. 7. Isothermal TPA result for the disproportionation of $\mathrm{Nd}_{12.5} \mathrm{Fe}_{80.9} \mathrm{~B}_{6.4} \mathrm{Nb}_{0.2}$ alloy carried out at various temperatures under an initial hydrogen pressure of $0.02 \mathrm{MPa}$.

containing $\mathrm{Nd}_{12.5} \mathrm{Fe}_{(81.1-(\mathrm{x}+\mathrm{y}))} \mathrm{B}_{6.4} \mathrm{Ga}_{\mathrm{x}} \mathrm{Nb}_{\mathrm{y}}$ alloys also fitted the parabolic rate law. The disproportionation of the NdFe-B alloy follows either a linear relationship or parabolic rate law depending on the disproportionation conditions, particularly the hydrogen pressure during the disproportionation [14]. Under a higher hydrogen pressure, the disproportionation reaction usually follows a linear relationship with a time-independent reaction rate. In this case, the transport of hydrogen atoms (or ions) might be more rapid than the chemical reaction involved in the disproportionation, and the reaction itself will be ratelimiting. The linear relationship suggests that the reaction product is not continuous; i.e., severe cracks may form in the reaction product (Fig. 9(a)) and allow hydrogen gas to remain in contact with the hydrogenated material and maintain a constant reaction rate. Under a low hydrogen pressure, the disproportionation reaction usually follows

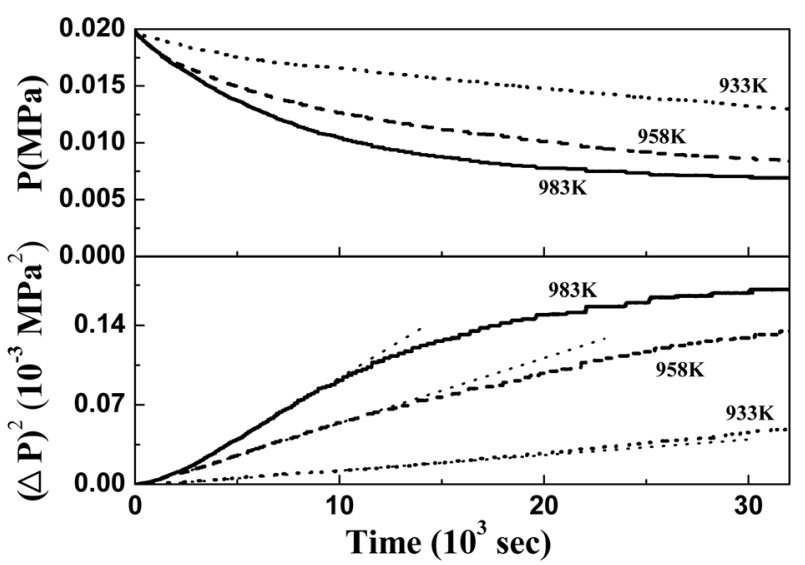

Fig. 8. Isothermal TPA result for the disproportionation of $\mathrm{Nd}_{12.5} \mathrm{Fe}_{80.6} \mathrm{~B}_{6.4} \mathrm{Ga}_{0.3} \mathrm{Nb}_{0.2}$ alloy carried out at various temperatures under an initial hydrogen pressure of $0.02 \mathrm{MPa}$.
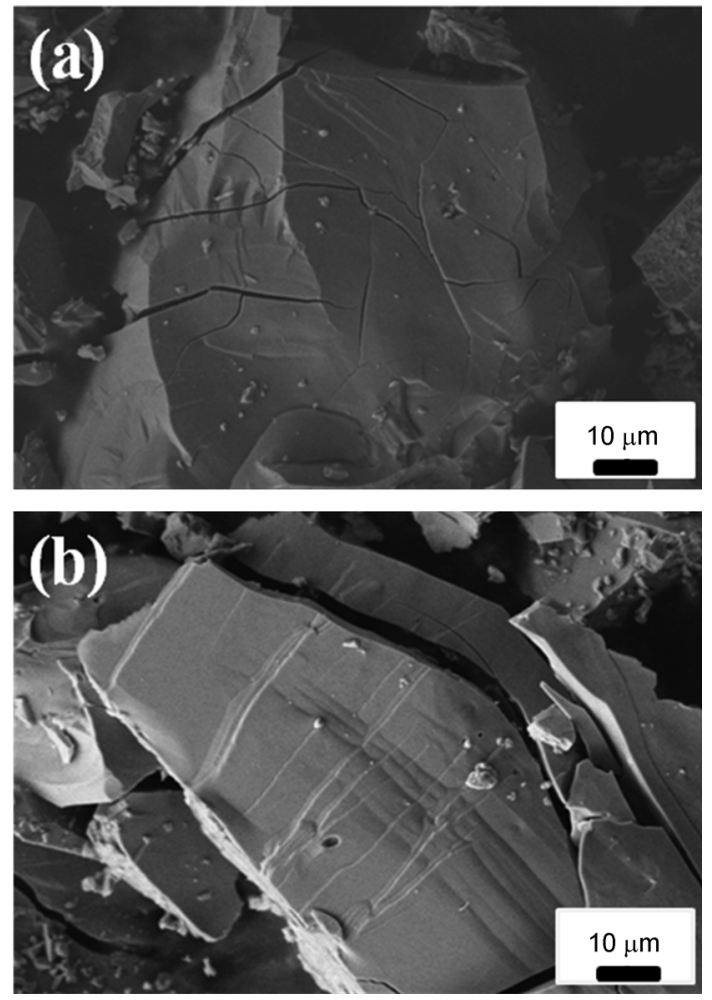

Fig. 9. SEM images showing the particle morphology of the $\mathrm{Nd}_{12.5} \mathrm{Fe}_{80.6} \mathrm{~B}_{6.4} \mathrm{Ga}_{0.3} \mathrm{Nb}_{0.2}$ alloy disproportionated (a) at $928 \mathrm{~K}$ for $5.5 \mathrm{hrs}$ with an initial hydrogen pressure of $0.1 \mathrm{MPa}$, (b) at $983 \mathrm{~K}$ for $8.5 \mathrm{hrs}$ with an initial hydrogen pressure of 0.02 MPa.

the parabolic rate law. The parabolic rate law suggests that the reaction product is continuous (Fig. 9(b)), and the diffusion of hydrogen atoms (or ions) through the reaction product may be more sluggish than the chemical reaction involved in the disproportionation process. In this case, the diffusion of hydrogen atoms (or ion) through the reaction product may be the rate-limiting process. Therefore, during the disproportionation of $\mathrm{Nd}_{12.5} \mathrm{Fe}_{(81.1-(x+y))^{-}}$ $\mathrm{B}_{6.4} \mathrm{Ga}_{\mathrm{x}} \mathrm{Nb}_{\mathrm{y}}$ alloys with an initial hydrogen pressure of $0.02 \mathrm{MPa}$, a continuous disproportionation product forms, i.e. a mixture of $\mathrm{NdH}_{\mathrm{x}}, \alpha-\mathrm{Fe}$ and $\mathrm{Fe}_{2} \mathrm{~B}$, and the overall reaction rate is limited by the diffusion of hydrogen atoms (or ions).

Fig. 5 shows the Arrhenius plots of the disproportionation of the Nd-Fe-B alloys containing Ga and/or Nb. The slope of the Arrhenius plot was higher for the alloys containing $\mathrm{Ga}$ and/or $\mathrm{Nb}$. The alloy with the combined addition of $\mathrm{Ga}$ and $\mathrm{Nb}$ has the steepest slope. The activation energies of the disproportionation reaction of the $\mathrm{Nd}_{12.5} \mathrm{Fe}_{(81.1-(\mathrm{x}+\mathrm{y}))} \mathrm{B}_{6.4} \mathrm{Ga}_{\mathrm{x}} \mathrm{Nb}_{\mathrm{y}}$ alloys were calculated, and are summarized in Table 1 . The combined addition of $\mathrm{Ga}$ and $\mathrm{Nb}$ appears to increase the activation energy significantly. The addition of Ga stabilizes the iron boride phase 
Table 1. Activation energy of the disproportionation reaction of the $\mathrm{Nd}_{12.5} \mathrm{Fe}_{(81.1-(\mathrm{x}+\mathrm{y}))} \mathrm{B}_{6.4} \mathrm{Ga}_{\mathrm{x}} \mathrm{Nb}_{\mathrm{y}}$ alloys.

\begin{tabular}{cccc}
\hline \hline \multicolumn{5}{c}{ alloy } \\
\hline $\mathrm{Ga}=0$ & 0.3 & 0 & 0.3 \\
$\mathrm{Nb}=0$ & 0 & 0.2 & 0.2 \\
\hline \multicolumn{5}{c}{ activation energy $(\mathrm{kJ} /$ mole H) } \\
\hline 189 & 251 & 256 & 321 \\
\hline
\end{tabular}

in the $\mathrm{Nd}-\mathrm{Fe}-\mathrm{B}$ alloy and the addition of $\mathrm{Nb}$ suppresses the excessive growth of the recombined grains. These findings suggest that in addition to these known effects, the addition of $\mathrm{Ga}$ and/or $\mathrm{Nb}$ significantly retards the disproportionation reaction of the $\mathrm{Nd}-\mathrm{Fe}-\mathrm{B}$ alloy. Highly anisotropic HDDR powder with good texture is normally produced by modifying the Nd-Fe-B alloy by the addition of $\mathrm{Ga}$ and $\mathrm{Nb}$ and adopting a lower hydrogen pressure for the disproportionation reaction. Both the lower hydrogen pressure during disproportionation and alloy modification with $\mathrm{Ga}$ and $\mathrm{Nb}$ retard the disproportionation kinetics remarkably, which is believed to help improve the texture of HDDR-treated Nd-Fe-B alloys.

\section{Conclusion}

The addition of $\mathrm{Ga}$ and, $\mathrm{Nb}$ retarded the disproportionation kinetics of the Nd-Fe-B alloy significantly with the combined addition of $\mathrm{Ga}$ and $\mathrm{Nb}$ having the most profound effect. The activation energy for the disproportionation of $\mathrm{Nd}_{12.5} \mathrm{Fe}_{(81.1-(\mathrm{x}+\mathrm{y}))} \mathrm{B}_{6.4} \mathrm{Ga}_{\mathrm{x}} \mathrm{Nb}_{\mathrm{y}}$ alloys was increased by adding $\mathrm{Ga}$ and, $\mathrm{Nb}$. The alloy containing both $\mathrm{Ga}$ and $\mathrm{Nb}$ had a much higher activation energy with respect to the other alloys. The disproportionation kinetic data of the $\mathrm{Nd}_{12.5} \mathrm{Fe}_{(81.1-(\mathrm{x}+\mathrm{y}))} \mathrm{B}_{6.4} \mathrm{Ga}_{\mathrm{x}} \mathrm{Nb}_{\mathrm{y}}$ alloys performed with an initial hydrogen pressure of $0.02 \mathrm{MPa}$ was fitted to a parabolic rate law. This suggests that during the disproportionation of the $\mathrm{Nd}_{12.5} \mathrm{Fe}_{(81.1-(\mathrm{x}+\mathrm{y}))} \mathrm{B}_{6.4} \mathrm{Ga}_{\mathrm{x}} \mathrm{Nb}_{\mathrm{y}}$ alloys with an initial hydrogen pressure of $0.02 \mathrm{MPa}$, a continuous disproportionation product was formed and the overall reaction rate was limited by the diffusion of hydrogen atoms (or ions).

\section{Acknowledgement}

This study was supported by a grant from the Fundamental R\&D Program for Core Technology of Materials funded by the Ministry of Knowledge Economy, Republic of Korea.

\section{References}

[1] T. Takeshita and R. Nakayama, Proc. 10th Int.Workshop RE Magnets and their Applications, 551 (1989).

[2] P. J. McGuiness, X. J. Zhang, X. J. Yin, and I. R. Harris, J. Less-Common Metals 158, 379 (1990).

[3] Nakamura, R. Suefuji, S. Sugimoto, M. Okada, and M. Homma, J. Appl. Phys. 76(10), 6828 (1994).

[4] S. Hirosawa, M. Uehara, S. Mino, and N. Ishigaki, J. Appl. Phys. 81(8), 4821 (1997).

[5] C. Mishima, N. Hamada, H. Mitarai, and Y. Honkura, Proc. 16th Int. Workshop RE Magnets and Their Applications, 873 (2000).

[6] O. Gutfleisch, B. Gebel, and N. Mattern, J. Magn. Magn. Mater. 210, 5 (2000).

[7] S. Sugimoto, N. Koike, D. Book, T. Kagotani, M. Okada, K. Inomata, and M. Homma, J. Alloys Comp. 330-332, 892 (2002).

[8] O. Gutfleisch, G. Drazic, C. Mishima, and Y. Honkura, IEEE Trans. Magn. 38, 2958 (2002).

[9] O. Gutfleisch, K. Khlopkov, A. Teresiak, K.-H. Müller, G. Drazic, C. Mishima, and Y. Honkura, IEEE Trans. Magn. 39, 2926 (2003).

[10] Jung-Hwan Kim and H. W. Kwon, J. Magnetics 10, 152 (2005).

[11] H. W. Kwon and J. H. Kim, J. Magn. Magn. Mater. 304, e222-e224 (2006).

[12] H. Nakamura, K. Kato, S. Sugimoto, M. Okada, and M. Homma, IEEE Trans. Magn. 35, 3274 (1999).

[13] C. Burkhardt, M. Steinhorst, and I. R. Harris, J. Alloy. Compd. 237, 113 (1996).

[14] H. W. Kwon and J. H. Yu, J. Alloy. Compd. 487, 138 (2009). 